ORIGINAL ARTICLE

\title{
Respiratory status in dairy farmers in France; cross sectional and longitudinal analyses
}

\author{
H Chaudemanche, E Monnet, V Westeel, D Pernet, A Dubiez, C Perrin, J-J Laplante, A Depierre, \\ J-C Dalphin
}

Occup Environ Med 2003;60:858-863

See end of article for authors' affiliations

.......................

Correspondence to: Prof. J-C Dalphin, Dept of Chest Diseases, CHUHôpital Jean Minjoz, Boulevard Fleming, 25030 Besançon CEDEX, France; jean-charles.dalphin@ ufc-chu.univ-fcomte.fr

Accepted

17 December 2002
Aims: To compare respiratory status in dairy farmers with that of non-farming controls. Methods: Longitudinal study in the Doubs (France). From a cohort constituted in 1994 (T1), 215 (81.1\%) dairy farmers and 110 (73.8\%) controls were reevaluated in 1999 (T2). The protocol comprised a medical and occupational questionnaire, spirometric tests at both evaluations, allergological tests at $\mathrm{T} 1$, and a noninvasive measure of blood oxygen saturation $\left(\mathrm{Spo}_{2}\right)$ at $\mathrm{T} 2$.

Results: In 1999 analyses, the prevalence of chronic bronchitis was higher ( $p=0.013$ ), and $\mathrm{FEV}_{1} / \mathrm{VC}$ $(p<0.025)$ and $\mathrm{Spo}_{2}(-0.7 \%, \mathrm{p}<0.01)$ lower in dairy farmers than in controls. In a multiple linear regression model, farming, age, and smoking were significantly and inversely correlated with $\mathrm{Spo}_{2}$. In the whole population, the mean annual decline in $\mathrm{FEV}_{1}$ and $\mathrm{FEV}_{1} / \mathrm{VC}$ was $-13.4 \mathrm{ml}$ and $-0.30 \%$, respectively. Farming was associated with an accelerated decline in $\mathrm{FEV}_{1} / \mathrm{VC}(\mathrm{p}<0.025)$ after adjustment for covariates. No relation between allergy and respiratory function changes was observed, except for $\mathrm{FEF}_{25-75}$.

Conclusions: This prospective study shows that dairy farming is associated with an excess of chronic bronchitis, with a moderate degree of bronchial obstruction and a mild decrease in $\mathrm{Spo}_{2}$.
$\mathrm{E}$ pidemiological studies have consistently shown a significant association between farming and an excess of respiratory symptoms. ${ }^{1-3}$ In a majority of cross sectional studies, respiratory function values are moderately although significantly lower in farmers when compared to nonfarming controls. There are only few controlled longitudinal studies $^{4}$ and interpretation of their results is difficult. ${ }^{5}$ Demonstration has nevertheless been made of an accelerated decline in expiratory flow rates and in forced vital capacity among grain elevator ${ }^{67}$ and swine confinement workers. ${ }^{8}$ These lung disorders may theoretically have repercussions on gas exchanges, but this has to our knowledge never been investigated. Their causes and mechanisms have not been not elucidated. ${ }^{1}$ Organic dust exposure seems to play a determinant role, especially in the development of chronic airflow obstruction. ${ }^{9}$ Farmers are indeed exposed to a large variety of organic particles that may be responsible for inflammatory or allergic pulmonary reactions. ${ }^{10}$ Moreover, allergy is considered as a possible risk factor for the development of chronic obstructive pulmonary disease (COPD) or for an accelerated decline in respiratory function parameters in the general population, ${ }^{11}{ }^{12}$ but its relation with respiratory function impairment has never been longitudinally studied in dairy farmers.

Two studies were conducted in two different geographic areas of the Doubs, a dairy farming province in France. The cross sectional analysis of the first study has shown a significant excess in respiratory symptoms and to a lesser degree in bronchial obstruction in farmers compared to nonfarming controls. ${ }^{13}$ The longitudinal analysis of the same cohort has suggested that long term occupational exposure significantly accelerated the decline in respiratory function in male dairy farmers. ${ }^{14}$ The present study concerns the second cohort. ${ }^{15}{ }^{16}$ In 1994, 265 dairy farmers were compared to 149 non-exposed control rural subjects. Results showed an excess of respiratory symptoms in dairy farmers which was mild and non-significant for asthma, but high for cough and phlegm.
There was also a non-reversible bronchial obstruction in dairy farmers. ${ }^{15}$ Prevalence of IgE mediated allergy was generally lower in dairy farmers. ${ }^{16}$ Both groups were reevaluated five years later with the following objectives:

- To confirm the excess of lung disorders in dairy farmers and to evaluate their influence on blood oxygenation by measuring non-invasively oxygen saturation.

- To compare respiratory function parameter changes in both groups and to analyse the influence of allergy on these modifications.

\section{METHODS}

This study was undertaken with the cooperation of the Doubs Mutualité Sociale Agricole (Agricultural Health Insurance Mutual), whose medical department organises annual free examinations for all affiliated members in the province. The protocol was approved by the local review board for research involving human subjects. Informed written consent was obtained from each subject.

\section{Population}

The study population in 1994 consisted of two groups of both genders, 16-65 years of age. Details of population selection have been described previously. ${ }^{15}$ Briefly, a cohort of 353 dairy farmers and 189 control subjects was established in 1994. Two hundred and sixty five and 149 of these subjects took part in the 1994 investigations, respectively.

In 1999, each subject investigated in 1994 was contacted individually and an explanatory letter concerning the

Abbreviations: $C P O D$, chronic obstructive pulmonary disease; $C S$ current smoker; $E S$, ex-smoker; $\mathrm{FEF}_{25-75}$, forced mid-expiratory flow; $\mathrm{FEV}_{1}$, forced expiratory volume in one second; NS, non-smoker; $\mathrm{Spo}_{2}$, blood oxygen saturation; VC, vital capacity 
Main messages

- Dairy farming is consistently associated with an excess of lung disorders, especially chronic bronchitis.

- Dairy farmers have a slight degree of chronic obstruction and of accelerated decline in expiratory flows.

- They have a mild but significant decrease in blood oxygen saturation independently of bronchial obstruction.

- Atopy does not seem to play a role in these disorders

objectives of the study, its practical value, and some of the previous results, was sent to each subject. Half of the subjects who refused to participate in the present study were randomly contacted in order to obtain the reasons for their refusal.

The protocol comprised a medical and occupational questionnaire, spirometric tests at both evaluations, allergological tests in 1994, and a non-invasive measure of blood oxygen saturation $\left(\mathrm{Spo}_{2}\right)$ in 1999.

\section{Questionnaires}

Medical questionnaires were collected during the organised medical examinations, and were reviewed by the same investigator as in 1994. This questionnaire consisted of an adapted French version of the long version of the European Community Respiratory Health Survey questionnaire. ${ }^{17}$ Questions on respiratory symptoms, allergy, and definition of chronic bronchitis, dyspnoea, and asthma have been given previously. ${ }^{15}$ Non-smokers (NS) were defined as those having smoked on average less than one cigarette, one cigar, or one pipe a day for a year. Current smokers (CS) smoked this amount or more, and ex-smokers (ES) had stopped smoking at least one month before the time at which they filled out the questionnaire.

\section{Respiratory function tests}

Respiratory function tests were performed according to the American Thoracic Society recommendations. ${ }^{18}$ A portable pneumotachograph (Autospiro Minato Pal; Medical Science Company Ltd, Osaka, Japan) was used to measure slow vital capacity (VC), forced expiratory volume in one second $\left(\mathrm{FEV}_{1}\right)$, and forced mid-expiratory flow $\left(\mathrm{FEF}_{25-75}\right)$. The spirometer was calibrated daily for atmospheric pressure, humidity, and temperature, and periodically with a 1.51 syringe. A minimum of three adequate measurements was required for each subject. Values were expressed as percentages of European Community for Steel and Coal reference values. ${ }^{19}$

\section{Immunological analyses}

Immunological analyses were performed in 1994. Methods and results of these analyses have been reported previously. ${ }^{16}$ Briefly, each subject underwent skin prick tests (SPT) on the volar surface of the forearm for seven allergens: Dermatophagoides pteronyssinus, Acarus siro, cow dander, cat dander, mixed grass pollen, mixed betulaceae pollen, and an extract of mixed mouldy and non-mouldy hay from farms in the Doubs (laboratoire des Stallergènes, Fresnes, France). Total IgE were measured by the microparticular enzymatic immunoassay (MEIA; IM X-IgE; Abbott, Rungis, France). Detection of serum IgE antibodies against a mixture of inhalant allergens was performed using the Phadiatop test with capsulated hydrophilic carrier method (Phadiatop, Cap system; Pharmacia Diagnostic AB, Uppsala, Sweden).
Policy implications

- A "simple" finger pulse oximeter may be a relevant tool for epidemiological studies of respiratory status.

\section{Oximetry data}

Arterial oxygen saturation was evaluated for each subject with the finger pulse oximeter Onyx model 9500 (Nonin Medical Inc., Plymouth, MN, USA). Three measurements at 30 second intervals were taken for each subject on the index finger of the left hand. Subjects were seated, and had been at rest for at least 15 minutes. The highest value of blood oxygen saturation using pulse oximetry $\left(\mathrm{Spo}_{2}\right)$ was retained with the corresponding pulse rate. The pulse oximeter was tested weekly for accuracy by comparing $\mathrm{Spo}_{2}$ with the oxygen saturation of arterial blood gases.

\section{Statistical analysis}

Total IgE was transformed logarithmically $\left(\log _{10}\right)$. For univariate analyses, discrete variables were compared through $\chi^{2}$ tests, and continuous variables using Student's $t$ tests. In multivariate models, adjustment was performed for potential confounders determined in the present analysis, but also for those generally considered as being determinants of respiratory function. Interactions were tested between all significant covariates. Assumption for residual normality was assessed by a normal probability plot of residuals.

First, a cross sectional analysis of 1999 data was performed to compare dairy farmers with controls. To correct for imbalances in age, sex, and smoking, a multiple logistic regression was used to compare the odds ratios for respiratory symptoms. Relations between lung function, $\mathrm{SpO}_{2}$ and pulse rate, and exposure (farmers) were assessed by multiple linear regression models. Adjustment was made for smoking (as pack-years) in the respiratory function model, and for age (as a continuous variable), sex, and smoking for both $\mathrm{Spo}_{2}$ and pulse rate models. Altitude (tableland versus plain), $\mathrm{FEV}_{1} / \mathrm{VC}$ (as a continuous variable), and $\log (\operatorname{IgE})$ were added in another model analysing $\mathrm{Spo}_{2}$.

Second, a longitudinal analysis of respiratory function was performed. Effect of exposure on the annual change in respiratory parameters ( ( 1999 value -1994 value)/number of years between the two visits) was tested by a multiple linear regression model adjusted for sex, height, the 1999 value of age, the number of pack-years smoked, and altitude. An analysis of variance and covariance with repeated measures was furthermore performed in order to evaluate the effect of covariates on respiratory function tests with no forward hypothesis of decline in lung function.

Statistical analyses were carried out using the BMDP statistical software package (BMDP, Los Angeles, CA, USA).

\section{RESULTS}

\section{Population characteristics}

The initial cohort included 414 subjects (T1). For the second evaluation (T2), 13 subjects were lost to follow up and four had died. Among the 397 remaining subjects, 325 (81.9\%) agreed to participate in the present study and were reevaluated. Among the 72 subjects who did not participate, 40 randomly selected subjects were contacted by telephone. Twenty one dairy farmers and 11 control subjects finally completed a telephone questionnaire. Reasons for refusal included lack of time (14 farmers, six controls), lack of interest for this kind of study (four farmers, two controls), impossibility to attend the medical evaluation because of occupational activities (one farmer, two controls), omission (one control), and medical reasons (two dairy farmers). 
Table 1 Demographic, clinical, spirometric, and allergological characteristics in 1994 for reevaluated and non-reevaluated farmers and control subjects

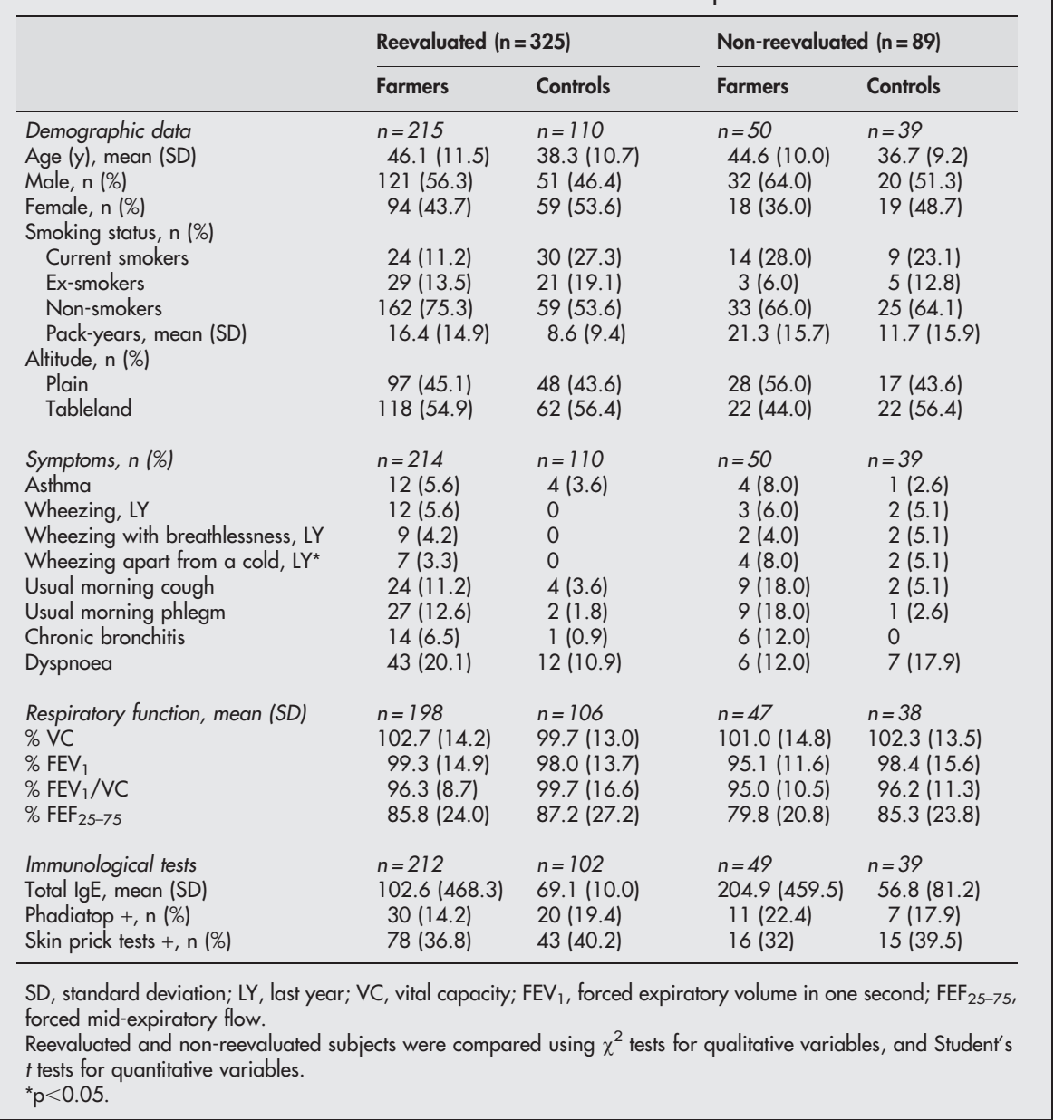

Individual characteristics, respiratory symptoms and function, and immunological evaluation at Tl were compared between reevaluated and non-reevaluated subjects (table 1). Non-reevaluated subjects were found to have slightly more respiratory symptoms and lower expiratory flow rates. For chronic bronchitis and $\mathrm{FEV}_{1}$, farmers were slightly more concerned by this loss of less healthy subjects than control subjects.

Table 2 presents individual characteristics of reevaluated dairy farmers and control subjects at T2. Seventy seven of the 215 dairy farmers had officially retired between 1994 and 1999, but 32 of them still had an occupational exposure.

\section{Cross sectional analyses}

Concerning respiratory symptoms, results show that the prevalence of atopy, asthma, and asthma related symptoms (attack of shortness of breath, woken by shortness of breath, wheezing, wheezing with breathlessness, and wheezing apart from a cold during the past year) was identical in both groups. Fourteen (6.6\%) farmers and seven (6.4\%) controls were self reported asthmatics. There was a higher prevalence of cough (15.9\%, p = 0.05), chronic phlegm (15.9\%, $\mathrm{p}=0.10)$, and chronic bronchitis $(7.5 \%, \mathrm{p}=0.013)$ in dairy farmers than in controls $(8.2 \%, 10 \%$, and $1.8 \%$, respectively) after adjustment for age, sex, and smoking. Smoking significantly influenced chronic bronchitis and related symptoms (cough, phlegm, wheezing).

Respiratory function data were available for 212 dairy farmers and 109 control subjects. There was no significant difference between both groups for VC (103.5\% for dairy farmers versus $100.5 \%$ for controls), $\mathrm{FEV}_{1}$ (101.5\% versus $100.4 \%$, respectively), and $\mathrm{FEF}_{25-75}$ (89.5\% versus $92.1 \%$, respectively). However, the $\mathrm{FEV}_{\mathrm{l}} / \mathrm{VC}$ ratio was significantly lower in exposed subjects $(98.2 \%$ versus $100.0 \%$, respectively, $\mathrm{p}<0.025)$. Smoking was negatively correlated with $\mathrm{FEV}_{1}$ and $\mathrm{FEV}_{1} / \mathrm{VC}(\mathrm{p}<0.01)$.

Table 2 Description of the study population in 1999

\begin{tabular}{|c|c|c|c|}
\hline & $\begin{array}{l}\text { Dairy farmers } \\
(n=215)\end{array}$ & $\begin{array}{l}\text { Control subjects } \\
(n=110)\end{array}$ & p value \\
\hline \multicolumn{4}{|l|}{ Age, $y$} \\
\hline Mean (SD) & $51.7(11.6)$ & $43.9(10.7)$ & $<0.001$ \\
\hline \multicolumn{4}{|l|}{ Height } \\
\hline Male, mean (SD) & $174.2(5.9)$ & $176.3(6.8)$ & $<0.05$ \\
\hline Smoking & $161.6(6.1)$ & $162.5(5.7)$ & \\
\hline Smokers, $>10$ pack & $15(6.9)$ & $14(12.7)$ & \\
\hline years, $\mathrm{n}(\%)$ & & & \\
\hline $\begin{array}{l}\text { Smokers, } \leq 10 \text { pack } \\
\text { years, } n(\%)\end{array}$ & $10(4.7)$ & $10(9.1)$ & $<0.001$ \\
\hline Ex-smokers, n (\%) & $27(12.6)$ & $28(25.5)$ & \\
\hline Non-smokers, n (\%) & $163(75.8)$ & $58(52.7)$ & \\
\hline Mean pack-years (SD) & $18.3(16.3)$ & $13.4(9.5)$ & NS \\
\hline Passive smoking, $n(\%)$ & $22(13.7)$ & $12(20.7)$ & NS \\
\hline \multicolumn{4}{|l|}{ Alcoholt } \\
\hline$<10 \mathrm{~g}, \mathrm{n}(\%)$ & $116(55.5)$ & 70 (67.3) & \\
\hline $10-50 \mathrm{~g}, \mathrm{n}(\%)$ & $88(42.1)$ & $33(31.7)$ & NS \\
\hline$>50 \mathrm{~g}, \mathrm{n}(\%)$ & $5(2.4)$ & $1(1.0)$ & \\
\hline
\end{tabular}


Table $3 \mathrm{SpO}_{2}$ and pulse rate in dairy farmers and controls in 1999

\begin{tabular}{llll}
\hline Available data & $\begin{array}{l}\text { Dairy farmers } \\
(\mathbf{n}=192)\end{array}$ & $\begin{array}{l}\text { Control subjects } \\
(\mathbf{n}=101)\end{array}$ & p value \\
\hline $\begin{array}{c}\mathrm{SpO}_{2} \\
\text { Mean (SD) }\end{array}$ & $96.9(1.4)$ & $97.6(1.2)$ & $<0.01^{*}$ \\
$\begin{array}{c}\text { Pulse rate } \\
\text { Mean (SD) }\end{array}$ & $71.2(11.0)$ & $74.4(13.8)$ & $\mathrm{NS}^{*}$ \\
\hline
\end{tabular}

*Multiple linear regression adjusted for age, sex, and smoking.

Table 3 presents results of $\mathrm{Spo}_{2}$ evaluation at $\mathrm{T} 2 . \mathrm{Spo}_{2}$ could not be measured in 32 subjects for the following reasons: failure of the pulse oximeter during an evaluation session (26 subjects) and impossible measure (six subjects). Comparisons of these 32 subjects with the other reevaluated subjects showed that they tended to be older $(p=0.08)$, lived at higher altitudes $(\mathrm{p}=0.05)$, and had more chronic bronchitis $(p=0.01)$, but that they were not significantly different with regard to spirometric values nor exposure (the fact of being or not a farmer). $\mathrm{Spo}_{2}$ was slightly but significantly lower in dairy farmers than in controls with a mean difference of $0.7 \%$. Distribution of $\mathrm{Spo}_{2}$ was similar in both groups; the difference was not explained by low values in a few farmers.

In a multiple linear regression model, dairy farming, age, and pack-years were inversely correlated with $\mathrm{Spo}_{2}$. Conversely the $\mathrm{FEV}_{1} / \mathrm{VC}$ ratio was positively correlated with $\mathrm{SpO}_{2}$ (table 4).

\section{Longitudinal analyses}

The longitudinal analysis of respiratory function tests could be performed in 301 subjects whose explorations were considered as being of good quality at both $\mathrm{Tl}$ and $\mathrm{T} 2$. Table 5 presents mean annual changes in respiratory function parameters between $\mathrm{T} 1$ and $\mathrm{T} 2$. VC was not found to decline. On the whole cohort, the mean annual decline in $\mathrm{FEV}_{1}$ and $\mathrm{FEV}_{\mathrm{l}} / \mathrm{VC}$ was $-13.4 \mathrm{ml}$ per year and $-0.30 \%$ per year, respectively. Farming was associated with an accelerated decline in $\mathrm{FEV}_{1} / \mathrm{VC}(\mathrm{p}<0.025)$ after adjustment for age, smoking, sex, height, $\log (\operatorname{IgE})$, altitude, and initial respiratory function values. Other factors associated with an accelerated decline in respiratory function were age, smoking in pack-years (for $\mathrm{FEV}_{1}$ /VC only, $\mathrm{p}<0.001$ ), height (for VC and $\left.\mathrm{FEV}_{1}\right)$, and initial lung function values. When the three indicators of allergy were separately tested in the model, the only significant relation was between total IgE and $\mathrm{FEF}_{25-75}$.

Table 4 Multiple regression model for blood oxygen saturation $\left(\mathrm{Spo}_{2}\right)$

\begin{tabular}{|c|c|c|c|}
\hline \multirow{2}{*}{$\begin{array}{l}\text { Independent } \\
\text { variables }\end{array}$} & \multicolumn{3}{|l|}{$\mathrm{SpO}_{2}$} \\
\hline & Coeff. & SE & $p$ value \\
\hline Exposure & -0.46 & 0.18 & $<0.01$ \\
\hline Male & -0.17 & 0.17 & NS \\
\hline Age & -0.02 & 0.07 & $<0.001$ \\
\hline Smoking & -0.03 & 0.08 & $<0.001$ \\
\hline Altitude & -0.12 & 0.15 & NS \\
\hline $\mathrm{FEV}_{1} / \mathrm{VC}$ & 0.03 & 0.01 & $<0.01$ \\
\hline $\log (\lg E)$ & -0.19 & 0.14 & NS \\
\hline Intercept & 96.75 & & \\
\hline$r^{2}$ & 0.25 & & \\
\hline
\end{tabular}

Regression coefficients (coeff.) with negative values indicate a negative relation. All variables listed were included simultaneously in the model; each coefficient and $p$ value is controlled for all other covariates. Age, smoking, $\log (\lg E)$, and $\mathrm{FEV}_{1} / \mathrm{VC}$ are continuous variables. Exposure: controls $=0$, farmers $=1$; altitude: plain $=0$, tableland $=1$. $\mathrm{SE}$, standard error.
Table 5 Mean annual changes in respiratory function parameters between 1994 and 1999

\begin{tabular}{lcc}
\hline & Farmers $(\mathbf{n}=196)$ & Controls $(\mathbf{n}=105)$ \\
\hline Time between the two & $5.83(0.27)$ & $5.62(0.43)$ \\
surveys (y) & $0.05(75.1)$ & $3.53(69.9)$ \\
$\Delta \mathrm{VC}, \mathrm{ml} / \mathrm{y}(\mathrm{SD})$ & $-16.58(48.9)$ & $-7.37(54.7)$ \\
$\Delta \mathrm{FEV}_{1}, \mathrm{ml} / \mathrm{y}(\mathrm{SD})$ & $-0.36(1.2)$ & $-0.19(1.1)$ \\
$\Delta \mathrm{FEV}_{1} / \mathrm{VC}, \% / \mathrm{y}(\mathrm{SD})$ & $11.38(116.7)$ & $-6.69(116.7)$ \\
$\Delta \mathrm{FEF}_{25-75}, \mathrm{ml} / \mathrm{y}(\mathrm{SD})$ & &
\end{tabular}

Except for total IgE, analysis of variance with repeated measures showed the same results as those presented in table 6 with, overall, more significant relations. In contrary to what was observed using the multiple linear regression model, total IgE were significantly correlated with the decline in $\mathrm{FEV}_{1}(\mathrm{p}<0.05)$.

\section{DISCUSSION}

Results of the current study are consistent with those of the 1994 cross sectional analysis and with those of other studies conducted in the same region. ${ }^{13-15}{ }^{20}$ Our findings confirmed that dairy farmers present a persistent excess in respiratory symptoms and a moderate bronchial obstruction which were not found to be closely related to IgE mediated allergy. In addition, our results suggest that these lung disorders are accompanied by a small but significant decrease in blood oxygen saturation.

Differences in the prevalence of respiratory symptoms between exposed and control subjects at T2 were smaller than those observed at $\mathrm{Tl}$ and only kept significance for chronic bronchitis and chronic cough. This may be partly explained by a loss of less healthy subjects at T2 (table 1). The prevalence of asthma was similar in both groups. The observed prevalence of $6 \%$ is lower than that published for the French general population ${ }^{21}$ but is usual in the farming setting. These results did not confirm those of a Swedish study in which the prevalence of asthma was found to double over a period of 12 years in dairy farmers. ${ }^{22}$ In this Swedish study, the authors insisted on the importance of allergy to storage mites, which do not seem to play a major role in our region. ${ }^{15}{ }^{16}$ Measures of lung function confirmed the tendency for bronchial obstruction in exposed subjects. Although still significant, the difference between farmers and controls was weaker than that observed at $\mathrm{Tl}$, possibly also because of a greater bronchial obstruction in non-reevaluated farmers (table 1).

This study is the first, to our knowledge, to measure $\mathrm{Spo}_{2}$ in farmers. There are no published recommendations for the use of pulse oximeters in epidemiological studies. All subjects were tested sitting at rest for at least 15 minutes, and the best of three measures was retained in the rare case of discrepancies between the three measures. A recent article suggested that the accuracy and reproducibility of $\mathrm{Spo}_{2}$ measures allowed the use of a pulse oximeter for epidemiological studies. ${ }^{23}$ Our results showed that $\mathrm{Spo}_{2}$ was significantly lower in dairy farmers. The fact that $\mathrm{Spo}_{2}$ was, as expected, correlated negatively to smoking and positively to the $\mathrm{FEV}_{1} / \mathrm{VC}$ ratio argues in favour of both the accuracy and relevance of the tool. Interestingly, after adjustment for $\mathrm{FEV}_{1} /$ $\mathrm{VC}$, exposure remained associated with a decreased $\mathrm{Spo}_{2}$. This suggests that other mechanisms than bronchial obstruction are involved. Exposure to organic dusts, including endotoxins, may induce inflammatory pulmonary reactions, ${ }^{102425}$ and therefore explain at least part of the decrease in $\mathrm{Spo}_{2}$. Finally it cannot be totally excluded that more callous hands in farmers play a role in the observed results. 
Table 6 Regression models for annual changes in lung function

\begin{tabular}{|c|c|c|c|c|c|c|c|c|}
\hline \multirow{2}{*}{$\begin{array}{l}\text { Independent } \\
\text { variables }\end{array}$} & \multicolumn{2}{|l|}{ vc } & \multicolumn{2}{|l|}{ FEV $_{1}$} & \multicolumn{2}{|c|}{$\mathrm{FEV}_{1} / \mathrm{VC}$} & \multicolumn{2}{|l|}{$\mathrm{FEF}_{25-75}$} \\
\hline & Coeff. & SE & Coeff. & SE & Coeff. & SE & Coeff. & SE \\
\hline Exposure & 7.94 & 9.23 & -3.80 & 6.54 & $-0.30 \dagger$ & 0.13 & -21.50 & 14.22 \\
\hline Age & $-1.79 \S$ & 0.43 & $-1.46 \S$ & 0.32 & $-0.03 \S$ & 0.01 & $-2.01 \ddagger$ & 0.66 \\
\hline Smoking & 0.02 & 0.43 & -0.49 & 0.31 & $-0.02 \S$ & 0.01 & $-1.53+$ & 0.65 \\
\hline Male & $50.42 \S$ & 14.35 & $20.78^{*}$ & 10.16 & -0.06 & 0.18 & $42.85^{\star}$ & 20.79 \\
\hline Height & $2.98 \S$ & 0.80 & $1.80 \ddagger$ & 0.54 & -0.01 & 0.01 & 2.00 & 1.10 \\
\hline Altitude & 7.63 & 8.15 & $4.48^{\circ}$ & 5.80 & 0.04 & 0.10 & -5.91 & 12.69 \\
\hline $\log (\lg E)$ & -6.72 & 7.71 & -9.30 & 5.48 & -0.19 & 0.10 & $-31.87 \ddagger$ & 11.88 \\
\hline Initial value & $-0.05 \S$ & 0.01 & $-0.04 \S$ & 0.01 & $-0.10 \S$ & 0.01 & $-0.06 \S$ & 0.01 \\
\hline Intercept & \multicolumn{2}{|r|}{-236.67} & \multicolumn{2}{|c|}{-127.20} & \multicolumn{2}{|r|}{11.81} & \multicolumn{2}{|c|}{7.28} \\
\hline$r^{2}$ & \multicolumn{2}{|r|}{0.18} & \multicolumn{2}{|c|}{0.14} & \multicolumn{2}{|r|}{0.40} & \multicolumn{2}{|c|}{0.22} \\
\hline
\end{tabular}

A regression coefficient (coeff.) with a negative value indicates that the variable is associated with a decline of the lung function parameter. All listed variables were included simultaneously in the models; each coefficient and $p$ value is controlled for all other covariates. Age, smoking, height, $\log (\lg \mathrm{E})$, and initial values are continuous variables; exposure: controls $=0$, farmers $=1$; altitude: plain $=0$, tableland $=1$. ${ }^{*} p<0.05, \uparrow p<0.025, \neq p<0.01, \S p<0.001$.

The longitudinal analysis showed that absolute values of VC were not significantly modified between T1 and T2 and that the decline in $\mathrm{FEV}_{1}$ and $\mathrm{FEV}_{1} / \mathrm{VC}$ was lower than expected (table 5). Such observations have been previously discussed. ${ }^{26}{ }^{27}$ A learning effect and/or a too small number of reevaluations in our study may have played a role. Another possible explanation is that exclusion of 28 subjects from the longitudinal analysis might have led to the selection of a healthier population. Indeed, subjects encountering difficulties performing respiratory function tests have generally the worst values. ${ }^{28}$ Moreover, subjects excluded at $\mathrm{Tl}$ for this reason were mainly farmers. This may have resulted in an underestimation of the magnitude of lung function decrease in farmers. Nevertheless, the effect of exposure on the $\mathrm{FEV}_{1}$ / VC ratio was statistically significant (table 6), even if it is controversial to adjust for initial values. ${ }^{5}$ Adjustment for initial values can lead to an overcorrection and to an underestimation of the effect of exposure. The variancecovariance analysis, which takes into account correlations between repeated measures in a same subject without making hypotheses on the sense of the difference between $\mathrm{T} 1$ and T2 reproduced the results presented in table 6, with a significance at least equal to that obtained using the multiple linear regression model. We can therefore conclude that our farmers have an accelerated decline in expiratory flow rates.

We also tested the influence of allergy on respiratory function changes. Several studies, recently reviewed ${ }^{11} 12$ suggested that allergy might be an independent risk factor for the development of COPD and for an accelerated decline in lung function in the general population. In Finish farmers, studies $^{29}{ }^{30}$ showed that atopy (defined clinically and/or by positive skin prick tests to usual aeroallergens) was significantly correlated with chronic bronchitis. In a previous study, we had observed that IgG mediated allergy was associated with an accelerated decline in the $\mathrm{FEV}_{\mathrm{l}} / \mathrm{VC}$ ratio. ${ }^{20}$ In the current study, however we did not observe consistent correlations between indicators of IgE mediated allergy and lung function or oxygen blood saturation.

In conclusion, this study shows that dairy farming is associated with an excess of lung disorders which mostly consist of chronic bronchitis, and with a moderate degree of bronchial obstruction and a mild decrease in blood oxygen saturation. Allergy does not seem to play a significant role.

\section{ACKNOWLEDGEMENTS}

The authors wish to thank Agnès Tarallo, Michèle Grenet, Marie Gainet, Ahmed Lounici, Christine Henriot, and Francine Kauffmann for their helpful collaboration.

\section{Authors' affiliations}

H Chaudemanche, V Westeel, D Pernet, A Dubiez, C Perrin, A Depierre, J-C Dalphin, Department of Chest Diseases, University Hospital, Besançon, France

E Monnet, Department of Public Health, University Hospital, Besançon, France

J-J Laplante, Medical Department of the "Mutualité Sociale Agricole du Doubs", Besançon, France

The study was supported by the SERF Group (EA 2276), French Ministry of National Education, Research and Technology, and by the CNMRT ("Comité National de lutte contre les Maladies Respiratoires et la Tuberculose")

\section{REFERENCES}

1 American Thoracic Society. Respiratory health hazards in agriculture. Am J Respir Crit Care Med 1998;158:S1-76.

2 May JJ, Schenker MB. Agriculture. In: Harber P, Schenker MB, Balmes JR, eds. Occupational and environmental respiratory disease. St Louis: Mosby, 1996:617-36.

3 Chan-Yeung M, Enarson DA, Kennedy SM. The impact of grain dust on respiratory health. Am Rev Respir Dis 1992;145:476-87.

4 Iversen M. Predictors of long-term decline of lung function in farmers. Monaldi Arch Chest Dis 1997;52:474-8.

5 American Thoracic Society. European Respiratory Society. Longitudinal data analysis workshop. Am J Respir Crit Care Med 1996;154:S277-84.

6 Chan-Yeung M, Dimich-Ward H, Enarson DA, et al. Five cross-sectional studies of grain elevator workers. Am J Epidemiol 1992;136:1269-79.

7 Enarson D, Vedal S, Chan-Yeung M. Rapid decline in $\mathrm{FEV}_{1}$ in grain handlers. Am Rev Respir Dis 1985;132:814-17.

8 Senthilselvan A, Dosman JA, Kirychuk SP, et al. Accelerated lung function decline in swine confinement workers. Chest 1997;111:1733-41.

9 Christiani DC. Organic dust exposure and chronic airway disease. Am J Respir Crit Care Med 1996;154:833-4.

10 Rylander R, Peterson Y. Causative agents for organic dust related disease. Am J Ind Med 1994;25:1-148.

11 Postma DS, Rijcken B. The role of atopy and hyperresponsiveness in the development of COPD. Eur Respir Rev 1997;7:159-62.

12 O'Connor GT, Sparrow D, Weiss ST. The role of allergy and nonspecific airway hyperresponsiveness in the pathogenesis of chronic obstructive pulmonary disease. Am Rev Respir Dis 1989;140:225-52.

13 Dalphin JC, Bildstein F, Pernet D, et al. Prevalence of chronic bronchitis and respiratory function in a group of dairy farmers in the French Doubs province. Chest 1989;95:1244-7.

14 Dalphin JC, Maheu MF, Dussaucy A, et al. Six year longitudinal study of respiratory function in dairy farmers in the Doubs province. Eur Respir J 1998; 11:1287-93.

15 Dalphin JC, Dubiez A, Monnet E, et al. Prevalence of asthma and respiratory symptoms in dairy farmers in the French province of the Doubs. Am J Respir Crit Care Med 1998; 158:1493-8.

16 Dubiez A, Meyer V, Gora D, et al. Prévalence de l'allergie immédiate aux pneumallergènes chez les agriculteurs fourragers du Doubs. Rev Epidém et Santé Publ 1995;43:470-6.

17 Burney P, Luczynska C, Chinn S, et al. The European Community Respiratory Health Survey. Eur Respir J 1994:7:954-60.

18 American Thoracic Society. Standardization of spirometry: 1987 update. Am Rev Respir Dis 1987; 136:1285-98.

19 Quanjer PH. Standardised lung function testing. Bull Eur Physiopathol Respir 1983;19(suppl 5):1-95s. 
20 Westeel V, Julien S, De Champs C, et al. Relationships of $\lg E$ and $\lg G$ sensitisation to respiratory function in dairy farmers. Eur Respir J 2000;16:886-92.

21 Neukirch F, Pin I, Knani J, et al. Prevalence of asthma and asthma-like symptoms in three French cities. Respir Med 1995;89:685-92.

22 Kronqvist M, Johansson E, Pershagen G, et al. Increasing prevalence of asthma over 12 years among dairy farmers on Gotland, Sweden: storage mites remain dominant allergens. Clin Exp Allergy 1999:29:35-41.

23 Arden Pope III C, Dockery DW, Kanner RE, et al. Oxygen saturation, pulse rate, and particulate air pollution. Am J Respir Crit Care Med 1999;159:365-72.

24 Larsson K, Malberg P, Eklund A, et al. Exposure to microorganisms, airway inflammatory changes and immune reactions in asymptomatic dairy farmers. Int Arch Allergy Appl Immunol 1988;87:127-33.
25 Clapp WD, Becker S, Quay J, et al. Grain dust-induced airflow obstruction and inflammation of the lower respiratory tract. Am J Respir Crit Care Med 1994; 150:611-17.

26 Burrows B, Lebowitz MD, Camilli $A E$, et al. Longitudinal changes in forced expiratory volume in one second in adults. Am Rev Respir Dis 1986:133:974-80.

27 Glindmeyer HW, Diem JE, Jones RN, et al. Noncomparability of longitudinal and cross-sectionally determined annual change in spirometry. Am Rev Respir Dis 1982; 125:544-8.

28 Eisen EA, Robins JM. Estimation of ventilatory capacity in subjects with unacceptable lung function tests. Int J Epidemiol 1986;15:337-42.

29 Vohlonen I, Terho EO, Horsmanheimo M, et al. Prevalence of chronic bronchitis in farmers according to smoking and atopic skin sensitisation. Eur J Respir Dis 1987;152(suppl): 175-80.

30 Terho EO, Koskenvuo M, Kaprio J. Atopy: a predisposing factor for chronic bronchitis in Finland. J Epidemiol Community Health 1995;49:296-8.

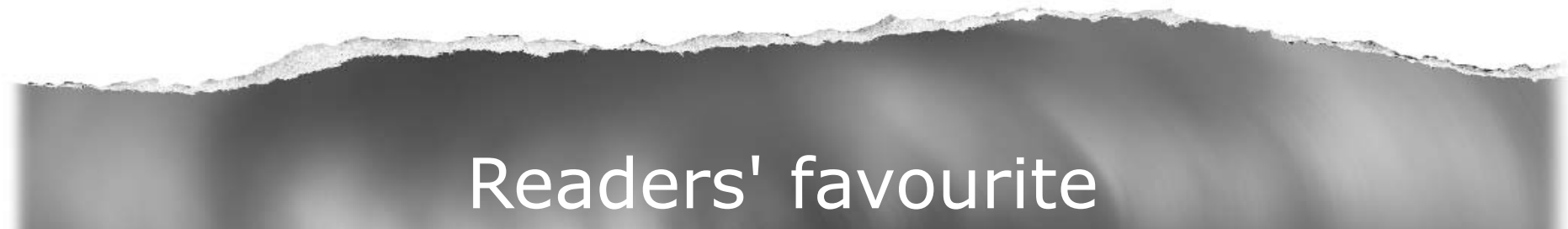

\section{Top 10}

Click on the "Top 10" button on the homepage to see which are the best read articles each month

www.occenvmed.com 